\title{
Impact of Age, Race and Ethnicity on Dialysis Patient Survival and Kidney Transplantation Disparities
}

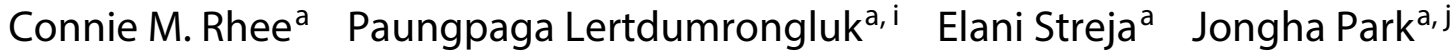 \\ Hamid Moradi $^{a}$ Wei Ling Lau ${ }^{a}$ Keith C. Norris ${ }^{b, c}$ Allen R. Nissenson ${ }^{c, e}$ \\ Alpesh N. Amin ${ }^{f}$ Csaba P. Kovesdyg,h Kamyar Kalantar-Zadeha, c, d \\ ${ }^{a}$ Harold Simmons Center for Kidney Disease Research and Epidemiology, Division of Nephrology and Hypertension, \\ University of California Irvine Medical Center, Orange, Calif., ${ }^{b}$ Drew University of Medicine, ' $D a v i d$ Geffen School of \\ Medicine at UCLA and d Department of Epidemiology, Fielding School of Public Health at UCLA, Los Angeles, Calif., \\ eDaVita Inc., El Segundo, Calif., ' Department of Medicine, University of California Irvine Medical Center, Irvine, Calif., \\ and ${ }^{9}$ Division of Nephrology, Memphis Veterans Affairs Medical Center, and h Division of Nephrology, University \\ of Tennessee Health Science Center, Memphis, Tenn., USA; ${ }^{i}$ Royal Irrigation Hospital, Srinakharinwirot University, \\ Nonthaburi, Thailand; 'Division of Nephrology, Ulsan University Hospital, University of Ulsan College of Medicine, \\ Ulsan, Republic of Korea
}

\section{Key Words}

Race $\cdot$ Ethnicity $\cdot$ Disparities $\cdot$ Survival · Transplantation

\begin{abstract}
Background: Prior studies show that African-American and Hispanic dialysis patients have lower mortality risk than whites. Recent age-stratified analyses suggest this survival advantage may be limited to younger age groups, but did not concurrently compare Hispanic, African-American, and white patients, nor account for differences in nutritional and inflammatory status as potential confounders. Minorities experience inequities in kidney transplantation access, but it is unknown whether these racial/ethnic disparities differ across age groups. Methods: The associations between race/ ethnicity with all-cause mortality and kidney transplantation were separately examined among 130,909 adult dialysis patients from a large national dialysis organization (entry period 2001-2006, follow-up through 2009) within 7 age cat-
\end{abstract}

egories using Cox proportional hazard models adjusted for case-mix and malnutrition and inflammatory surrogates. $\boldsymbol{R} \boldsymbol{e}$ sults: African-Americans had similar mortality versus whites in younger age groups (18-40 years), but decreased mortality in older age groups ( $>40$ years). In contrast, Hispanics had lower mortality versus whites across all ages. In sensitivity analyses using competing risk regression to account for differential kidney transplantation rates across racial/ethnic groups, the African-American survival advantage was limited to $>60$-years age categories. African-Americans and Hispanics were less likely to undergo kidney transplantation from all donor types versus whites across all ages, and these disparities were even more pronounced for living donor kidney transplantation (LDKT). Conclusions: Hispanic dialysis patients have greater survival versus whites across all ages; in African-Americans, this survival advantage is limited to patients $>40$ years of age. Minorities are less likely to undergo kidney transplantation, particularly LDKT, across all ages.

(c) 2014 S. Karger AG, Basel

\section{KARGER}

E-Mail karger@karger.com www.karger.com/ajn (c) 2014 S. Karger AG, Basel

0250-8095/14/0393-0183\$39.50/0
Kamyar Kalantar-Zadeh, MD, MPH, PhD

Harold Simmons Center for Kidney Disease Research and Epidemiology Division of Nephrology and Hypertension, University of California Irvine Medical Center 101 The City Drive South, City Tower, Suite 400-ZOT: 4088, Orange, CA 92868-3217 (USA) E-Mail kkz@uci.edu 


\section{Introduction}

In the past two decades, numerous kidney disease disparities have been identified among minority dialysis patients [1]. For example, African-Americans comprise $12.6 \%$ of the US population [2], but have a 3.5 -fold higher incidence of end-stage renal disease (ESRD) versus non-Hispanic whites [3]. African-Americans initiate renal replacement therapies at younger ages [4] and have poorer dialysis performance measures (i.e. lower dialysis doses [5] and arteriovenous fistula placement [6]). Although there is comparatively less data on health care disparities among Hispanic kidney disease patients, studies indicate that they experience a 1.5 -fold higher incidence of ESRD [3], less pre-ESRD care [7], and a reduced rate of kidney transplantation [8] versus non-Hispanic whites. Despite these inequities, population-level analyses show that African-American and Hispanic ESRD patients have a lower mortality risk versus non-Hispanic whites $[3,4$, 9-11], even after accounting for differences in age and comorbidity status [12].

Recent data suggest that the paradoxical survival advantage among African-Americans and Hispanics may be restricted to particular age groups. In a seminal study comparing African-American versus white dialysis patients, Kucirka et al. [13] reported that African-Americans have increased mortality risk in younger ( $\leq 50$ years) age groups and decreased mortality risk in older ( $>50$ years) age groups, but did not separately consider Hispanic ethnicity. Subsequently, Arce et al. [14] demonstrated that Hispanics initiating dialysis had lower mortality risk compared to non-Hispanic whites, but the magnitude of survival benefit was less pronounced in older age groups, and was attenuated when differential rates of kidney transplantation by ethnicity were accounted for. In the first study to compare Hispanic versus African-American versus non-Hispanic white dialysis patients, Yan et al. [15] showed that these racial/ethnic subgroups have the lowest, intermediate, and highest mortality risk, respectively, across almost all age groups, except for the youngest (1830 years) age group in which African-Americans had higher mortality risk versus non-Hispanic whites. However, a key limitation across these collective studies was the inability to account for racial/ethnic differences in nutritional and inflammatory status. Prior studies have shown that adjustment for nutritional and inflammatory markers attenuates the Hispanic survival advantage to the null and may in fact reverse the African-American survival advantage [16]. To date, there has not been direct examination of how age modifies the association between race, ethnic- ity, and survival after accounting for differences in nutritional and inflammatory status.

One of the most critical inequities experienced by minority dialysis patients is their impaired access to kidney transplantation. Kidney transplantation dramatically improves survival and quality of life, and it is considered the gold standard treatment among ESRD patients $[17,18]$. Numerous studies show that African-Americans and Hispanics have decreased access to living donor kidney transplantation (LDKT) and deceased donor kidney transplantation (DDKT), but it is not known if these disparities exist across all categories of age [19-22]. Thus to better inform the field, we sought to examine age as a modifier of the association between African-American and Hispanic race/ethnicity with (1) all-cause death and (2) receipt of kidney transplantation in a contemporary cohort of patients with detailed information on sociodemographics, comorbidities, and laboratory data from a large national dialysis organization.

\section{Materials and Methods}

\section{Study Population}

We examined data from all individuals with ESRD who underwent hemodialysis or peritoneal dialysis in one of the DaVita Inc. outpatient dialysis facilities during an entry period of July 1, 2001 to June 30, 2006 with follow-up through June 30, 2009. The study was approved by the institutional review committees of the Los Angeles Biomedical Research Institute at Harbor-UCLA and DaVita Clinical Research. Given the large sample size, anonymity of the patients studied, and nonintrusive nature of the research, requirement for consent was exempted.

The baseline quarter was the calendar quarter in which the patient's dialysis vintage was $>90$ days. Patients who were $\geq 18$ years of age, had a dialysis vintage of $>90$ days, received dialysis during the baseline quarter, and of non-Hispanic white, non-Hispanic black, or Hispanic race/ethnicity were included. In this report, the former two groups are referred to as whites and African-Americans, respectively. Asian and American Indian racial groups were not included due to small sample size.

Race/Ethnicity, Demographic and Comorbidity Measures

Creation of the cohort has previously been described [23]. Information on race/ethnicity, primary insurance, marital status, and presence of diabetes at baseline were obtained from the DaVita database. Race/ethnicity was self-reported by dialysis patients according to the race/ethnicity they most closely identified with according to US Census Bureau categorizations [2].

To minimize measurement variability, repeated laboratory and clinical measurements for each patient during the calendar quarter of entry (baseline quarter) were averaged. Dialysis vintage was defined as the time between the first day of dialysis treatment and the study entry date. Posthemodialysis dry weight and baseline height were used to calculate BMI. Data on baseline comorbidities, active 
tobacco smoking, and drug and alcohol dependence (current/ within the past 10 years) were obtained by linking the DaVita database to US Renal Data System (USRDS) Medical Evidence Form 2728 data using patients' names, dates of birth, and social security numbers.

\section{Laboratory Measures}

Blood samples were drawn using standardized techniques in all DaVita dialysis clinics and were transported to the DaVita Laboratory in Deland (Fla.) typically within $24 \mathrm{~h}$, and were measured using automated and standardized methods in the DaVita laboratory. Most laboratory parameters [i.e. urea nitrogen, albumin, creatinine, total iron binding capacity (TIBC), bicarbonate, phosphorous, calcium, and normalized protein catabolic rate (nPCR)] were measured monthly; ferritin and intact parathyroid hormone were measured at least quarterly. Hemoglobin was measured at least monthly in all patients and weekly to biweekly in most patients. Most blood samples were collected before dialysis, except for postdialysis serum urea nitrogen to calculate urea kinetics.

\section{Outcome Ascertainment}

The primary outcomes of interest were (1) all-cause death and (2) receipt of kidney transplantation from all donor types, which were ascertained from the DaVita and USRDS databases. We first evaluated the association between race/ethnicity and all-cause mortality using Cox proportional hazard models in which patients remained at-risk until death or censoring for kidney transplantation or end of the study (June 30, 2009). In sensitivity analyses, we examined mortality risk using competing risk regression according to the Fine and Gray method $[13,24]$, in which death was the outcome of interest and transplantation was treated as a competing risk as opposed to a censoring event. In contrast to Cox regression mortality hazard ratios which assume that different racial/ethnic groups undergo kidney transplantation at equivalent rates, competing risk regression mortality subhazard ratios account for differential transplantation rates among whites, AfricanAmericans, and Hispanics.

We then examined the association between race/ethnicity and receipt of kidney transplantation from all donor types using Cox proportional hazards models. In secondary analyses, we separately examined categories of kidney transplantation according to donor status: (1) LDKT (including living related and unrelated donors), (2) living related donor kidney transplantation (LRDKT), (3) living unrelated donor kidney transplantation (LUDKT), and (4) DDKT, which were ascertained through linkage to the Scientific Registry of Transplant Recipients database using patients' names, dates of birth, and social security numbers. In kidney transplantation analyses, patients were censored for death events or at the end of the study.

\section{Statistical Analyses}

Baseline characteristics within each race/ethnicity and age category were analyzed as proportions, means (SD), or medians according to data type. Crude death and transplantation rates within strata of age and race/ethnicity were calculated as the number of events per 100,000 patient-days of follow-up. We evaluated the association between race/ethnicity and all-cause mortality within 7 age categories $(18-30,>30$ to $40,>40$ to $50,>50$ to $60,>60$ to 70 , $>70$ to 80 , and $>80$ years). Due to a low frequency of transplantation events within the $>80$-years age category, the association be- tween race/ethnicity and receipt of kidney transplantation was estimated within 6 age categories only (18-30, $>30$ to $40,>40$ to 50 , $>50$ to $60,>60$ to 70 , and $>70$ to 80 ). For each analysis, we examined two models with incremental multivariable adjustment for baseline covariates. In case-mix models, we adjusted for covariates employed in prior studies of age, race, ethnicity, and survival [13-15], and in fully adjusted models, we additionally adjusted for markers of nutritional status and inflammation and other confounders of the race/ethnicity-mortality association.

Case-mix adjusted models included age, sex, insurance (Medicare, Medicaid, private, and other), entry calendar quarter, BMI category $(<18,18$ to $<25,25$ to $<30,30$ to $<35$, $\geq 35$ ), modality (peritoneal or hemodialysis), diabetes, smoking, alcohol dependence, drug dependence, and 8 baseline comorbidities from the USRDS Medical Evidence Form 2728 (atherosclerotic heart disease, cardiac failure, hypertension, cerebrovascular disease, peripheral vascular disease, chronic obstructive pulmonary disease, malignancy, and nonambulatory state).

Fully adjusted models included all case-mix model covariates plus marital status (married, divorced, single, or widowed), vintage ( $<6$ months, 6 to $<24$ months, and $2-5$ years, $>5$ years), residual renal function, dialysis dose (single pool Kt/V), serum phosphate, and nutritional status and inflammation surrogates (serum albumin, TIBC, calcium, bicarbonate, creatinine, ferritin, hemoglobin, peripheral white blood cell count, lymphocyte percentage, and nPCR) during the baseline quarter.

There was no missing data with regards to age, sex, diabetes, and vintage. Data for modality was missing for $<1 \%$ of the cohort. Data for insurance, marital status, and comorbidities had 8.4, 17.3, and $5.1 \%$ missing values, respectively. Data for residual renal function, BMI, single pool Kt/V, nPCR, albumin, creatinine, TIBC, bicarbonate, phosphorus, calcium, ferritin, hemoglobin, white blood cell count, and lymphocyte percentage were 18.8, 16.8, 24.4, 24.6, $15.1,17.3,18.5,15.6,14.9,14.8,22.5,13.8,16.3$, and $21.0 \%$, respectively. For continuous variables, missing covariate data were imputed by the means or medians of the existing values, and for categorical variables a missing indicator was created. Plots of $\log [-\log$ (survival rate)] against log (survival time) were used to check the proportionality assumption. Statistical analyses were conducted with SAS, version 9.1 (SAS Institute Inc., Cary, N.C., USA).

\section{Results}

\section{Cohort Description}

The cohort initially included 164,789 patients (online suppl. fig. 1; for all online suppl. material, see www. karger.com/doi/10.1159/000358497). After excluding patients $<18$ years of age, those whose vintage was $<90$ days, and of other or unknown race/ethnicity, the final study cohort consisted of 130,909 patients in 1 of $3 \mathrm{mu}-$ tually exclusive race/ethnicity categories: whites (49\%; $\mathrm{n}=64,710)$, African-Americans (35\%; $\mathrm{n}=45,718)$, and Hispanics $(16 \% ; n=20,481)$.

Table 1 shows patients' baseline demographic, clinical, and laboratory characteristics across race/ethnicity 


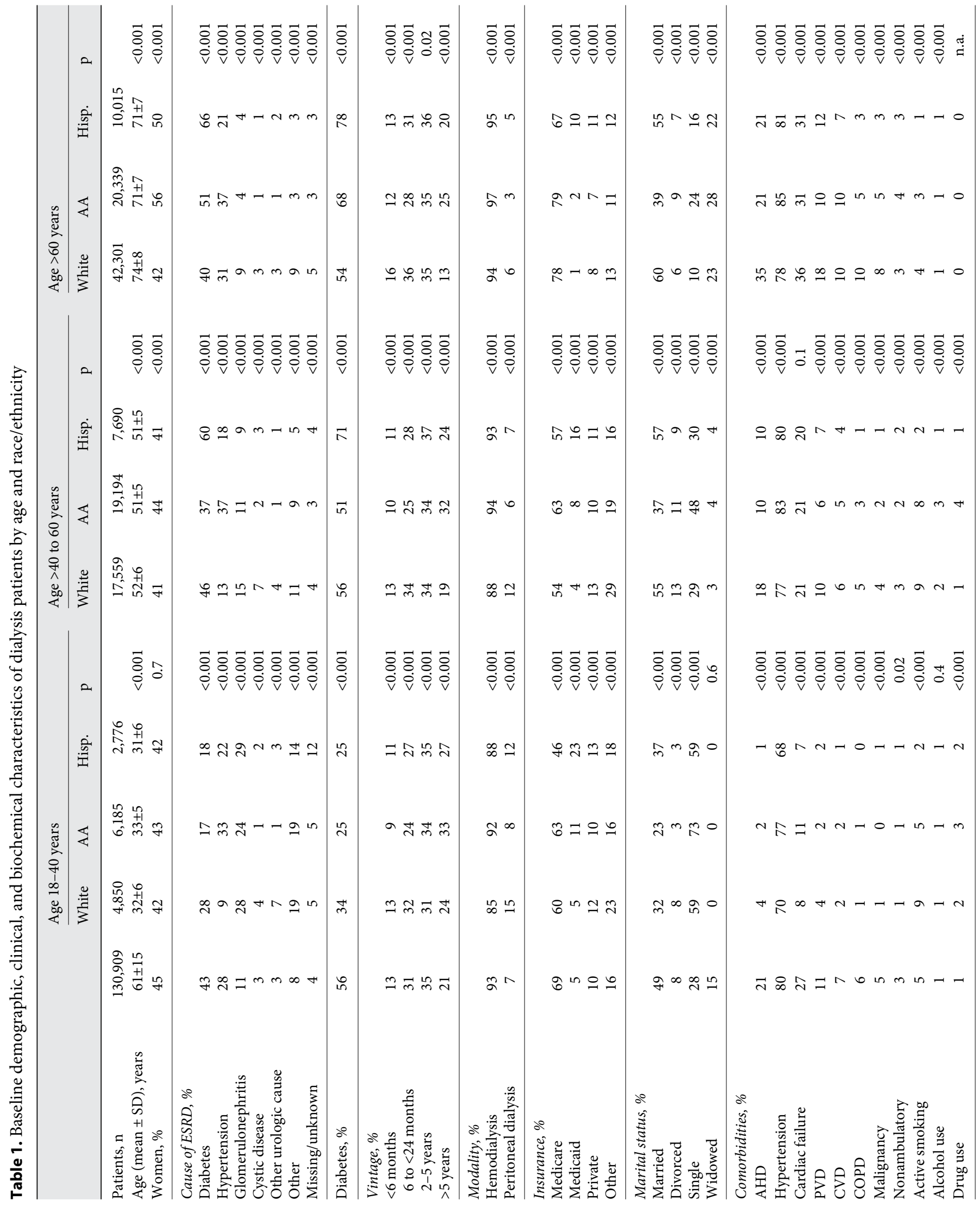




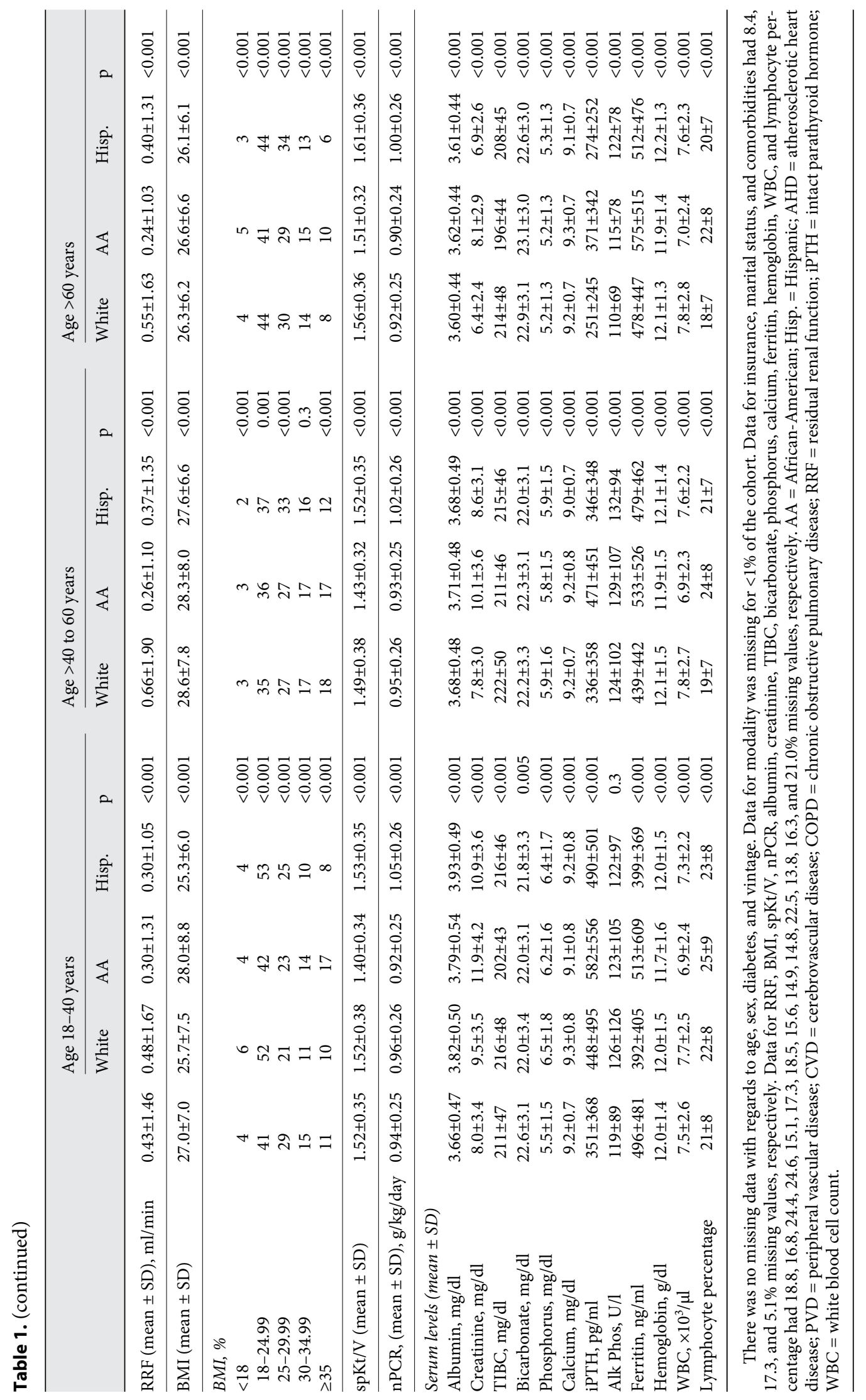




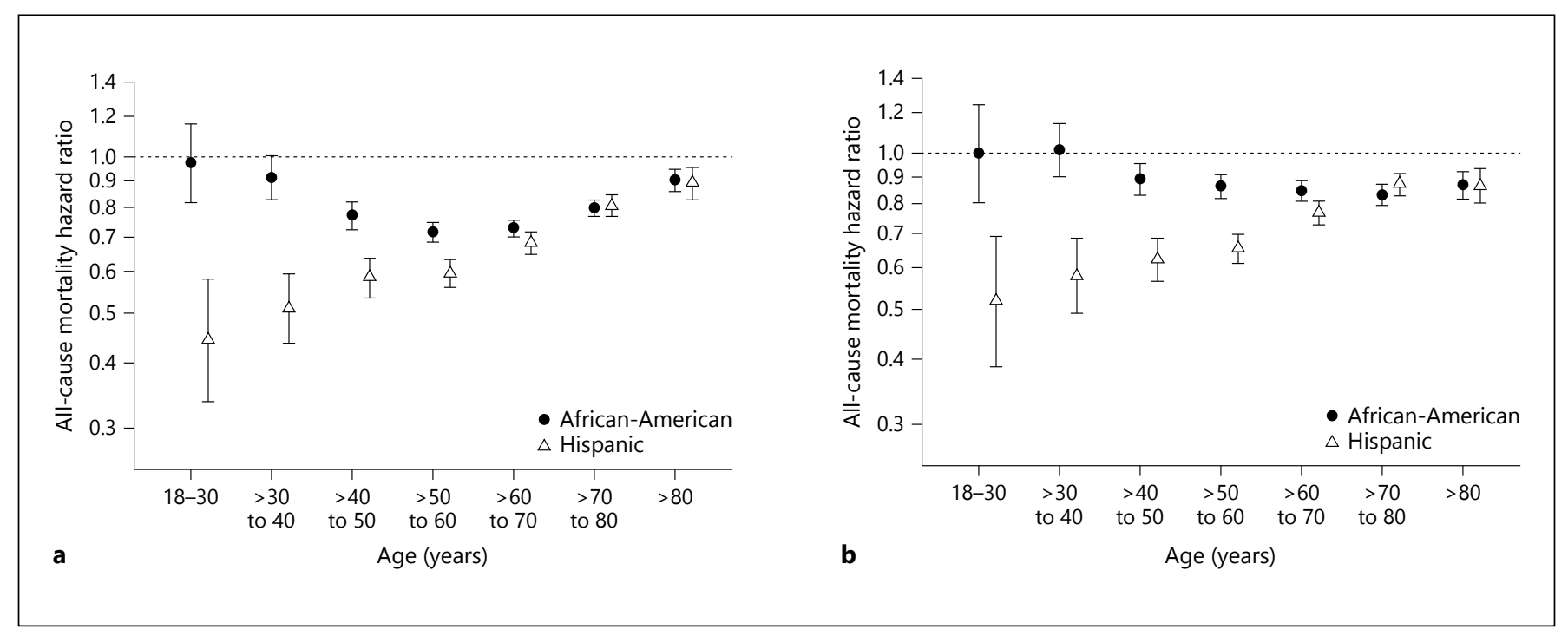

Fig. 1. All-cause mortality hazard ratios (95\% CI) across 7 age categories using case-mix (a) and fully adjusted (b) Cox regression models comparing 45,718 African-American and 20,481 Hispanic with 64,710 non-Hispanic white (reference) dialysis patients. Er- ror bars represent $95 \% \mathrm{CI}$. Number of patients per age category: $18-30$ years $(n=4,356),>30$ to 40 years $(n=9,464),>40$ to 50 years $(\mathrm{n}=17,670),>50$ to 60 years $(\mathrm{n}=26,792),>60$ to 70 years $(30,383)$, $>70$ to 80 years $(28,446)$, and $>80$ years $(13,798)$. and age categories. Compared to whites, a greater proportion of African-Americans and Hispanics were in younger age categories. Across all ages, AfricanAmericans and Hispanics had a higher prevalence of increased ( $>5$ years) vintage, higher mean serum creatinine, and lower prevalence of vascular disease versus whites. In younger and middle age categories (18-40 and $>40$ to 60 years), African-Americans had a higher prevalence of Medicaid/Medicare and lower prevalence of private insurance, and Hispanics had a higher prevalence of Medicaid across all age categories versus whites. In middle and older age categories (40-60 and $>60$ years), Hispanics had a higher prevalence of diabetes and hypertension versus whites and African-Americans. The most prevalent causes of ESRD within racial/ethnic groups varied across age categories. In the younger age category, $40 \%$ of Hispanics had diabetes or hypertension as the cause of ESRD, compared to $50 \%$ of AfricanAmericans and $37 \%$ of whites. However, in the middle and older age categories, $78 \%$ and $87 \%$ of Hispanics had diabetes or hypertension as the cause of ESRD, respectively, which exceeded or was equivalent to the prevalence in African-Americans and whites. In contrast, in the younger age category, $29 \%$ of Hispanic patients had glomerulonephritis as the cause of ESRD, representing the most prevalent etiology of disease, versus $24 \%$ in African-Americans and $28 \%$ in whites. However, in the middle and older age categories, $9 \%$ and $4 \%$ of Hispanic patients had glomerulonephritis, which was lower or equivalent to the prevalence in African-Americans and whites. Patients contributed a total of 363,713 patientyears of follow-up time, during which 72,891 deaths (39,708 whites, 23,262 African-Americans, and 9,921 Hispanics) and 12,677 kidney transplants (6,535 whites, 3,916 African-Americans, and 2,226 Hispanics) occurred (online suppl. tables 1,2). The median follow-up time was 2.4 years.

\section{All-Cause Mortality by Race/Ethnicity and Age Categories Using Cox Regression}

In case-mix analyses, African-Americans had similar all-cause mortality risk in younger age categories (18-30 and $>30$ to 40 years), but decreased mortality risk in age categories $>40$ years compared to whites (fig. 1; online suppl. table 3). In fully adjusted analyses, mortality reductions among African-Americans versus whites in the $>40$ - to 80 -years age categories were mildly attenuated but remained statistically significant. In case-mix analyses, Hispanics had a lower mortality risk versus whites across all ages, with the most potent survival advantage observed in younger age categories. In fully adjusted analyses, mortality reductions among Hispanics versus whites in the 18- to 80 -years age categories were mildly attenuated but remained statistically significant. Compared to 


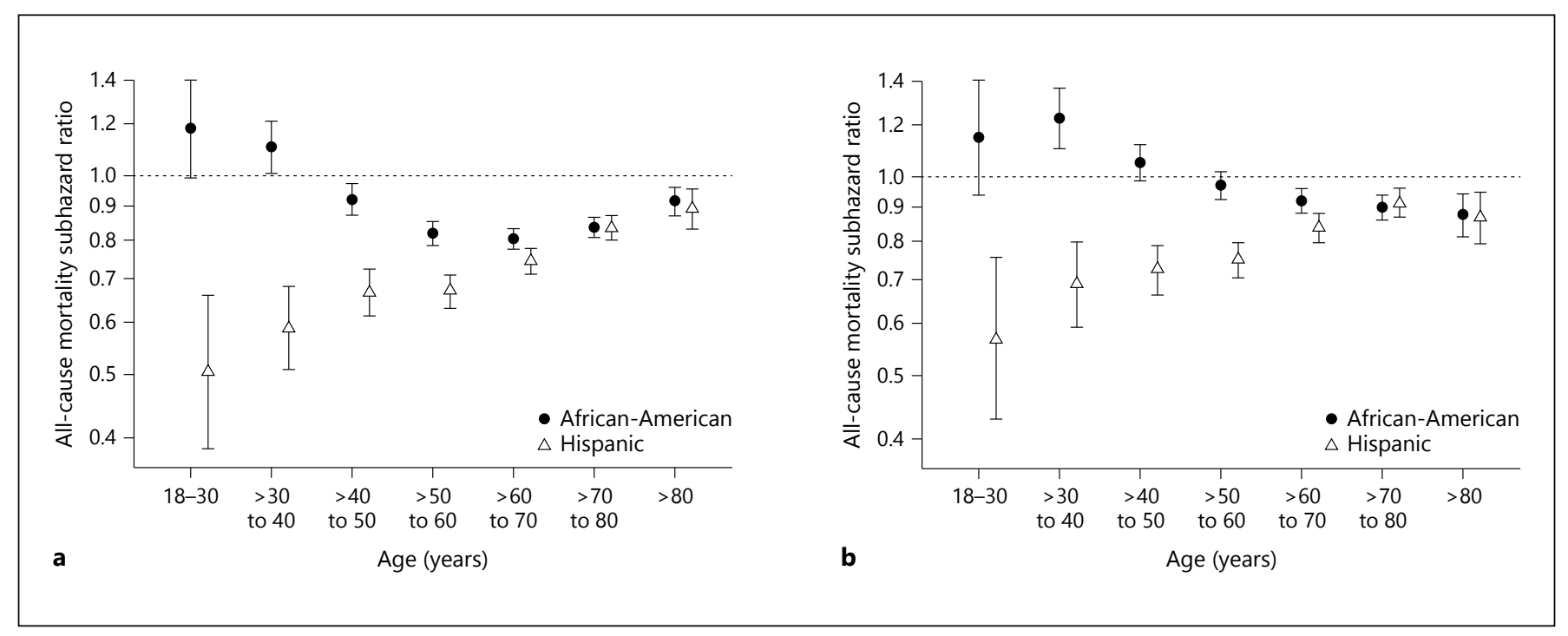

Fig. 2. All-cause mortality subhazard ratios across 7 age categories using case-mix (a) and fully adjusted (b) competing risk regression models comparing 45,718 African-American and 20,481 Hispanic with 64,710 non-Hispanic white (reference) dialysis patients. Er- ror bars represent $95 \% \mathrm{CI}$. Number of patients per age category: $18-30$ years $(\mathrm{n}=4,356),>30$ to 40 years $(\mathrm{n}=9,464),>40$ to 50 years $(\mathrm{n}=17,670),>50$ to 60 years $(\mathrm{n}=26,792),>60$ to 70 years $(30,383)$, $>70$ to 80 years $(28,446)$, and $>80$ years $(13,798)$.
Hispanics, African-Americans had increased mortality risk in the age categories 18-70 years in case-mix analyses, with the greatest survival differences observed in younger age categories (online suppl. fig. 2; online suppl. table 3); results from fully adjusted analyses were qualitatively similar.

\section{All-Cause Mortality by Race/Ethnicity and Age}

Categories Using Competing Risk Regression

In sensitivity analyses employing competing risk regression, African-Americans had similar, slightly higher, and decreased mortality risk versus whites within the age categories of $18-30,>30$ to 40 , and $>40$ years in case-mix analyses, respectively (fig. 2; online suppl. table 4). However, the magnitude of mortality risk reduction in older (>40 years) African-Americans was lower than observed in the Cox regression analyses. In fully adjusted analyses, this mortality risk reduction was further attenuated, such that older African-Americans had similar mortality risk versus whites within age categories of $>40$ to 60 years. In case-mix and fully adjusted analyses, the degree of survival benefit in Hispanics versus whites was lower than observed in the Cox regression analyses, whereas the degree of heightened mortality risk in African-Americans versus Hispanics was qualitatively similar to the Cox regression analyses.

Impact of Age, Race and Ethnicity on Dialysis and Kidney Transplantation

\section{Kidney Transplantation by Race/Ethnicity and Age} Categories

Among a total of 12,677 kidney transplantations, $7,132,3,347$, and 2,198 were from deceased, living, and unknown donors, respectively. Among LDKT, 2,131, 1,208 , and 8 were from related, unrelated, and unknown living donors, respectively. When kidney transplantations from all donor types were considered, both African-Americans and Hispanics were less likely to undergo transplantation versus whites across all ages, with greater disparities observed in older age categories in case-mix analyses (fig. 3; online suppl. table 5). Compared to Hispanics, African-Americans ages 18-70 years were also less likely to undergo transplantation in casemix analyses (online suppl. fig. 3; online suppl. table 5). Results from fully adjusted analyses showed similar findings.

When DDKT only was considered, there were no differences in transplantation among African-Americans versus whites and Hispanics versus whites in the 18- to 30 -years age category in case-mix analyses. However, both African-Americans and Hispanics were less likely to undergo DDKT versus whites in the $>30$ - to 80 -years age categories in case-mix analyses (online suppl. table 6). Results from fully adjusted analyses showed similar findings. Compared to Hispanics, African-Americans were less likely to undergo DDKT in the $>40$ - to 50 -years age category 


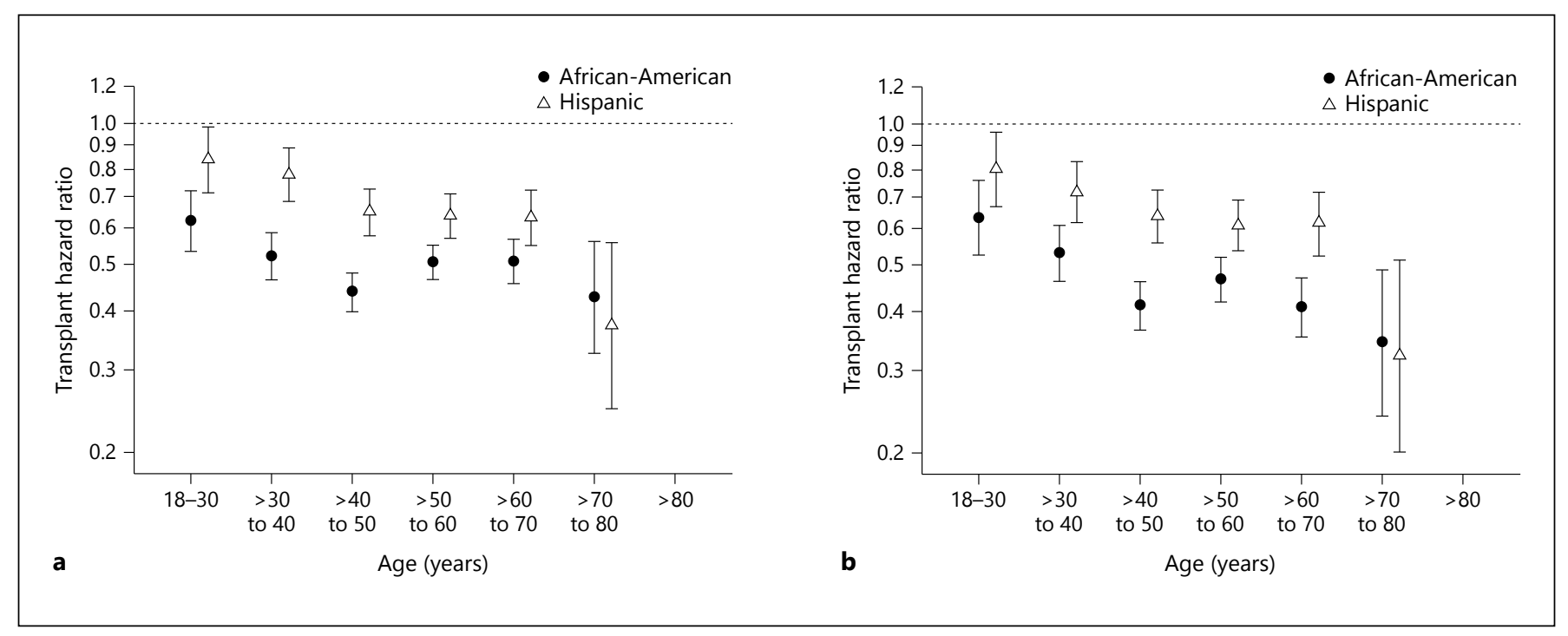

Fig. 3. Kidney transplantation hazard ratios across 6 age categories using case-mix (a) and fully adjusted (b) competing risk regression models comparing 45,718 African-American and 20,481 Hispanic with 64,710 non-Hispanic white (reference) dialysis patients. Error bars represent $95 \% \mathrm{CI}$. Age category $>80$ not included due to unstable estimates resulting from paucity of events. Number of patients per age category: $18-30$ years $(n=4,356),>30$ to 40 years $(\mathrm{n}=9,464),>40$ to 50 years $(\mathrm{n}=17,670),>50$ to 60 years $(\mathrm{n}=$ $26,792)$, $>60$ to 70 years $(30,383)$, and $>70$ to 80 years $(28,446)$.

differences in LUDKT among Hispanics versus African Americans across any of the age categories in case-mix or fully adjusted analyses.

\section{Discussion}

In this large, contemporary cohort of 130,909 US dialysis patients, we observed that Hispanic dialysis patients had greater survival compared to whites and African-Americans across virtually all age categories. African-Americans had greater survival compared to whites among patients exceeding 40 years of age in standard Cox regression analyses, and the magnitude of survival benefit was attenuated when racial/ethnic differences in kidney transplantation rates were accounted for in competing risk regression analyses. When examining kidney transplantations from all donor types, we observed that African-Americans and Hispanics were less likely than whites to undergo transplantation across all age categories. Disparities across race and ethnicity were particularly amplified for LDKT.

Our findings extend upon three recent USRDS studies suggesting that age is an important modifier of the racemortality association. In the first of these studies, Kucirka et al. [13] showed that the African-American survival ad- 
vantage is restricted to older ( $\geq 50$ years) dialysis patients, and that African-Americans $<50$ years of age had greater mortality risk compared to the white reference group which included both non-Hispanics and Hispanics. Hispanic dialysis patients have decreased mortality risk compared to non-Hispanic whites $[3,10,11]$, and their inclusion in the white reference group may have contributed to the higher mortality risk observed among younger African-Americans versus whites [15]. Arce et al. [14] then showed that the survival advantage among Hispanic white versus non-Hispanic white dialysis patients attenuated (1) with increasing age and (2) after accounting for differential rates of kidney transplantation across ethnicity, although patients of African-American race were not concomitantly examined. In a subsequent study by Yan et al. [15] that separately considered Hispanic dialysis patients from African-Americans and whites, a similar survival disadvantage was observed among younger AfricanAmericans versus whites, but did not consider racial/ethnic differences in rates of kidney transplantation. Furthermore, data limitations precluded the examination of nutrition and inflammatory status as potential confounders of the age, race/ethnicity, and mortality associations.

We observed several corroborative and novel findings as we sought to address these limitations by (1) concurrently examining race and ethnicity, (2) more comprehensively adjusting for sociodemographic variables (e.g. marital status) and repeated measures of laboratory covariates (e.g. malnutrition and inflammatory covariates) and dialysis treatment characteristics averaged in the baseline quarter $[16,25]$, and (3) accounting for differential rates of kidney transplantation across race/ethnicity. First, our study provides confirmatory evidence that older AfricanAmericans have increased survival versus whites, which was mildly attenuated with incremental adjustment for nutritional and inflammatory covariates. However, in contrast to the aforementioned studies, we observed a similar mortality risk among African-American dialysis patients versus whites in younger age (18-40 years) categories in both case-mix and fully adjusted Cox analyses. The underlying reasons for an attenuated survival advantage in younger African-Americans remains unclear; however, it has been suggested that biologic factors primarily mediate the race/ethnicity-mortality association in older patients [26] in whom Medicare eligibility offsets health care access inequities, whereas socioeconomic status, education, access to health care, and social support networks bear greater importance in younger populations $[13,27,28]$. After accounting for differential kidney transplantation rates across racial/ethnic groups using compet-

Impact of Age, Race and Ethnicity on Dialysis and Kidney Transplantation ing risks regression, the African-American survival advantage in older age groups was attenuated (and became nonexistent in the 40- to 60-years age group), suggesting that the paradoxical African-American advantage may in part be due to their comparatively lower rates of kidney transplantation versus whites. Further studies are needed to determine the underlying factors driving the differential African-American-mortality association across varying age groups.

Similar to the Arce et al. [14] study, we observed that Hispanic dialysis patients have greater survival compared to whites, particularly in younger age groups, and the degree of this survival benefit was mildly attenuated with adjustment for nutritional and inflammatory markers, as well as in competing risk regression analyses. We also showed for the first time that, among minority dialysis patients, Hispanics have decreased death risk compared to African-Americans across nearly all age categories, which was robust to incremental adjustment for laboratory covariates and after consideration of differential rates of transplantation. It has been posited that the Hispanic survival advantage compared to whites may be due to comparatively lower cardiovascular burden [14, 29], ethnic misclassification, or 'salmon bias' in which older ailing Hispanics return to their country of origin, resulting in an underreporting of deaths [30-32]. We also observed that older Hispanics had a markedly higher prevalence of diabetes and hypertension (also as the etiology of their ESRD) compared to their younger counterparts, which may explain the attenuation in the Hispanic survival benefit with increasing age. Further examination of the mechanisms underlying the Hispanic survival advantage compared to whites and African-Americans is needed.

Despite the disproportionate burden of ESRD among racial and ethnic minorities, population-based studies show that African-Americans and Hispanics are substantially less likely to receive DDKT [21] and LDKT compared with whites $[19,20,22]$. LDKT is the treatment of choice for dialysis patients given that it confers greater patient survival and quality of life compared with dialysis, as well as improved early graft function, lower rates of acute rejection, and greater graft and patient survival compared to DDKT [33-37]. To our knowledge, ours is the first study to show that African-Americans and Hispanics are less likely to undergo kidney transplantation across all age categories, and that these disparities are magnified for LDKT and particularly LUDKT. In contrast, racial/ethnic disparities in DDKT were not as marked as for LDKT, and were not consistently observed in younger age groups. 
Although our study does not elucidate determinants of inequitable kidney transplantation access, prior data shows that minorities encounter barriers at multiple steps (e.g. donor recruitment and conversion, transplant evaluation, and the kidney transplantation procedure itself), and that these barriers operate at multiple levels (recipients, donors, family and social support networks, health care providers and systems, and communities) $[36,38]$. For example, at the recipient and donor level, African-Americans are less likely to identify living kidney donors (particularly unrelated donors [39]) compared to whites [38], which may relate to inadequate education regarding ESRD treatment options [40], lack of medically suitable or willing donors [41], socioeconomic insecurity [42], and cultural beliefs [43]. Given that whites and African-Americans disproportionately contribute to the donor and recipient pools, respectively, genetic dissimilarity may be another factor for reduced DDKT rates among African-Americans and other minorities [44-46]. At the provider level, perceptions about patients' suitability and preferences for LDKT may differ by race/ethnicity, resulting in decreased transplant referral for minorities [47]. At the community level, sparsity of transplant centers in rural locations may contribute to reduced LDKT rates in minorities [48]. Rigorous studies are needed to elucidate mechanisms driving transplantation disparities across age, race, and ethnicity, and to explore interventions targeting these barriers $[36,37,49,50]$.

Our study has several strengths, which include its large sample size, extended follow-up period, and comprehensive availability of detailed sociodemographic, dialysis treatment, and laboratory data, including nutritional and inflammatory status covariates. However, several limitations bear mention. First, the findings presented may not be generalizable to patients from nonlarge dialysis organizations. Second, we had limited ability to distinguish Hispanic subpopulations which may have had differential severity of disease, survival, and access to transplantation depending on country of origin [51]. Third, we cannot exclude the possibility that the survival advantage observed in older African-Americans may have been due to a natural selection bias of the healthiest patients $[13,27,28]$. Fourth, our data do not distinguish steps at which racial/ethnic and age disparities in the transplantation process may occur, nor the underlying reasons for failure to progress to sequential stages. Fifth, baseline comorbidity data was ascertained from the Medical Evidence 2728 form in which comorbidities may have been underreported and severity of disease cannot be ascertained. Finally, as with all observational studies, we cannot exclude the possibility of residual confounding.

\section{Conclusion}

In conclusion, we observed that the African-American survival advantage was restricted to middle- and olderaged dialysis patients, whereas Hispanics experience greater survival across all ages. We also observed that African-American and Hispanic dialysis patients were less likely to undergo kidney transplantation, particularly LDKT, across all age groups. Awareness of the differential race/ethnicity-mortality associations across age categories in dialysis patients has important implications, as misconceptions regarding survival advantage may diminish the urgency with which providers refer minorities for transplantation. Given the disproportionate burden of ESRD among African-Americans and Hispanics, further mechanistic studies are needed to determine the genetic, biologic, socioeconomic, and psychosocial factors underlying the differential survival and access to transplantation among racial/ethnic groups, and timely interventions and policy-level changes targeting the most vulnerable subgroups are needed.

\section{Acknowledgements}

The study was supported by K.K.-Z.'s research grants from the NIH/NIDDK (R01 DK078106, K24 DK091419) and a philanthropist grant from Mr. Harold Simmons. C.M.R. was supported by an NIH/NIDDK grant (F32 DK093201). K.C.N. is supported in part by NIH grants (U54MD007598, UL1RR033176, P30AG021684 and P20-MD000182).

\section{Disclosure Statement}

K.K.-Z. was medical director of DaVita Harbor-UCLA Long Beach from 2007-2012. A.R.N. is Chief Medical Officer of DaVita Inc. None of the other authors declare any relevant conflicts of interest.

References

Rhee et al.

\footnotetext{
1 Powe NR: Let's get serious about racial and ethnic disparities. J Am Soc Nephrol 2008;19: 1271-1275.

2 Humes KR, Jones NA, Ramirez RR: Overview of race and Hispanic origin: 2010. 2010 Census Briefs. 2011. http://www.census.gov/ $\mathrm{prod} / \mathrm{cen} 2010 / \mathrm{briefs} / \mathrm{c} 2010 \mathrm{br}-02 . \mathrm{pdf}$ (accessed August 29, 2012).
} 
3 US Renal Data System. US Renal Data System 2011 Annual Data Report: Atlas of Chronic Kidney Disease and End-Stage Renal Disease in the United States. Bethesda, National Institute of Diabetes and Digestive and Kidney Diseases, 2011.

4 Agodoa L, Eggers P: Racial and ethnic disparities in end-stage kidney failure-survival paradoxes in African-Americans. Semin Dial 2007;20:577-585.

5 Owen WF Jr, Chertow GM, Lazarus JM, Lowrie EG: Dose of hemodialysis and survival: differences by race and sex. JAMA 1998;280: 1764-1768.

-6 Wasse H, Hopson SD, McClellan W: Racial and gender differences in arteriovenous fistula use among incident hemodialysis patients. Am J Nephrol 2010;32:234-241.

$\checkmark 7$ Kausz AT, Obrador GT, Arora P, Ruthazer R, Levey AS, Pereira BJ: Late initiation of dialysis among women and ethnic minorities in the United States. J Am Soc Nephrol 2000;11: 2351-2357.

$\checkmark 8$ Sequist TD, Narva AS, Stiles SK, Karp SK, Cass A, Ayanian JZ: Access to renal transplantation among American Indians and Hispanics. Am J Kidney Dis 2004;44:344-352.

-9 Bleyer AJ, Tell GS, Evans GW, Ettinger WH Jr, Burkart JM: Survival of patients undergoing renal replacement therapy in one center with special emphasis on racial differences. Am J Kidney Dis 1996;28:72-81.

10 Frankenfield DL, Rocco MV, Roman SH, McClellan WM: Survival advantage for adult Hispanic hemodialysis patients? Findings from the end-stage renal disease clinical performance measures project. J Am Soc Nephrol 2003:14:180-186

11 Kalantar-Zadeh K, Kovesdy CP, Derose SF, Horwich TB, Fonarow GC: Racial and survival paradoxes in chronic kidney disease. Nat Clin Pract Nephrol 2007;3:493-506.

12 Mesler DE, McCarthy EP, Byrne-Logan S, Ash AS, Moskowitz MA: Does the survival advantage of nonwhite dialysis patients persist after case mix adjustment? Am J Med 1999;106:300-306.

13 Kucirka LM, Grams ME, Lessler J, Hall EC, James N, Massie AB, Montgomery RA, Segev DL: Association of race and age with survival among patients undergoing dialysis. JAMA 2011;306:620-626.

-14 Arce CM, Goldstein BA, Mitani AA, Winkelmayer WC: Trends in relative mortality between Hispanic and non-Hispanic whites initiating dialysis: a retrospective study of the US Renal Data System. Am J Kidney Dis 2013;62: 312-321.

-15 Yan G, Norris KC, Yu AJ, Ma JZ, Greene T, $\mathrm{Yu}$ W, Cheung AK: The relationship of age, race, and ethnicity with survival in dialysis patients. Clin J Am Soc Nephrol 2013;8:953961.

16 Streja E, Kovesdy CP, Molnar MZ, Norris KC, Greenland S, Nissenson AR, Kopple JD, Kalantar-Zadeh K: Role of nutritional status and inflammation in higher survival of African
American and Hispanic hemodialysis patients. Am J Kidney Dis 2011;57:883-893.

17 Evans RW, Manninen DL, Garrison LP Jr, Hart LG, Blagg CR, Gutman RA, Hull AR, Lowrie EG: The quality of life of patients with end-stage renal disease. N Engl J Med 1985; 312:553-559.

18 Wolfe RA, Ashby VB, Milford EL, Ojo AO, Ettenger RE, Agodoa LY, Held PJ, Port FK Comparison of mortality in all patients on dialysis, patients on dialysis awaiting transplantation, and recipients of a first cadaveric transplant. N Engl J Med 1999;341:17251730.

19 Gore JL, Danovitch GM, Litwin MS, Pham PT, Singer JS: Disparities in the utilization of live donor renal transplantation. Am J Transplant 2009;9:1124-1133.

20 Hall EC, James NT, Garonzik Wang JM, Berger JC, Montgomery RA, Dagher NN, Desai NM, Segev DL: Center-level factors and racial disparities in living donor kidney transplantation. Am J Kidney Dis 2012;59:849-857.

21 Hall YN, Choi AI, Xu P, O’Hare AM, Chertow GM: Racial ethnic differences in rates and determinants of deceased donor kidney transplantation. J Am Soc Nephrol 2011;22:743751.

22 Purnell TS, Xu P, Leca N, Hall YN: Racial differences in determinants of live donor kidney transplantation in the United States. Am J Transplant 2013;13:1557-1565.

23 Miller JE, Kovesdy CP, Nissenson AR, Mehrotra R, Streja E, Van Wyck D, Greenland S, Kalantar-Zadeh K: Association of hemodialysis treatment time and dose with mortality and the role of race and sex. Am J Kidney Dis 2010;55:100-112.

24 Fine JP, Gray RJ: A proportional hazards model for the subdistribution of a competing risk. J Am Stat Assoc 1999;94:496-509.

25 Foley RN, Collins AJ: The USRDS: what you need to know about what it can and can't tell us about ESRD. Clin J Am Soc Nephrol 2013; 8:845-851.

26 Hoogeveen EK, Halbesma N, Rothman KJ, Stijnen T, van Dijk S, Dekker FW, Boeschoten EW, de Mutsert R: Obesity and mortality risk among younger dialysis patients. Clin J Am Soc Nephrol 2012;7:280-288.

27 Mehrotra R, Kermah D, Fried L, Adler S, Norris $\mathrm{K}$ : Racial differences in mortality among those with CKD. J Am Soc Nephrol 2008;19: 1403-1410.

28 Norris KC, Kalantar-Zadeh K, Kopple JD: The role of race in survival among patients undergoing dialysis. Nephrol News Issues 2011;25:13-14, 16.

29 Peralta CA, Shlipak MG, Fan D, Ordonez J, Lash JP, Chertow GM, Go AS: Risks for endstage renal disease, cardiovascular events, and death in Hispanic versus non-Hispanic white adults with chronic kidney disease. J Am Soc Nephrol 2006;17:2892-2899.

30 Abraido-Lanza AF, Dohrenwend BP, NgMak DS, Turner JB: The Latino mortality paradox: a test of the 'salmon bias' and healthy migrant hypotheses. Am J Public Health 1999; 89:1543-1548

31 Hunt KJ, Williams K, Resendez RG, Hazuda HP, Haffner SM, Stern MP: All-cause and cardiovascular mortality among diabetic participants in the San Antonio Heart Study: evidence against the 'Hispanic paradox'. Diabetes Care 2002;25:1557-1563.

32 Patel KV, Eschbach K, Ray LA, Markides KS: Evaluation of mortality data for older Mexican Americans: implications for the Hispanic paradox. Am J Epidemiol 2004;159:707-715.

33 Cecka M: Clinical outcome of renal transplantation. Factors influencing patient and graft survival. Surg Clin North Am 1998;78: 133-148.

-34 Jofre R, Lopez-Gomez JM, Moreno F, SanzGuajardo D, Valderrabano F: Changes in quality of life after renal transplantation. Am J Kidney Dis 1998;32:93-100.

-35 Molnar MZ, Streja E, Kovesdy CP, Shah A, Huang E, Bunnapradist S, Krishnan M, Kopple JD, Kalantar-Zadeh K: Age and the associations of living donor and expanded criteria donor kidneys with kidney transplant outcomes. Am J Kidney Dis 2012;59:841-848.

36 Purnell TS, Hall YN, Boulware LE: Understanding and overcoming barriers to living kidney donation among racial and ethnic minorities in the United States. Adv Chronic Kidney Dis 2012;19:244-251.

- 37 Waterman AD, Rodrigue KR, Purnell TS, Ladin K, Boulware LE: Addressing racial and ethnic disparities in live donor kidney transplantation: priorities for research and intervention. Semin Nephrol 2010;30:90-98.

-38 Weng FL, Reese PP, Mulgaonkar S, Patel AM: Barriers to living donor kidney transplantation among black or older transplant candidates. Clin J Am Soc Nephrol 2010;5:23382347.

39 Reeves-Daniel A, Bailey A, Assimos D, Westcott C, Adams PL, Hartmann EL, Rogers J, Farney AC, Stratta RJ, Daniel K, Freedman BI: Donor-recipient relationships in African American vs. Caucasian live kidney donors. Clin Transplant 2011;25:E487-E490.

40 Boulware LE, Meoni LA, Fink NE, Parekh RS, Kao WH, Klag MJ, Powe NR: Preferences, knowledge, communication and patient-physician discussion of living kidney transplantation in African American families. Am J Transplant 2005;5:1503-1512.

41 Lunsford SL, Simpson KS, Chavin KD, Menching KJ, Miles LG, Shilling LM, Smalls GR, Baliga PK: Racial disparities in living kidney donation: is there a lack of willing donors or an excess of medically unsuitable candidates? Transplantation 2006;82:876-881.

42 Navaneethan SD, Singh S: A systematic review of barriers in access to renal transplantation among African Americans in the United States. Clin Transplant 2006;20:769-775.

43 Gordon EJ: Patients' decisions for treatment of end-stage renal disease and their implications for access to transplantation. Soc Sci Med 2001;53:971-987.
Impact of Age, Race and Ethnicity on Dialysis and Kidney Transplantation
Am J Nephrol 2014;39:183-194 DOI: $10.1159 / 000358497$ 
44 Cecka JM, Rajalingam R, Zhang J, Reed EF: Histocompatibility testing, crossmatching, and immune monitoring; in Danovitch GM (ed): Handbook of Kidney Transplantation, ed 5. Philadelphia, Lippincott Williams and Wilkins, 2010, pp 36-60

45 Gaston RS, Danovitch GM, Adams PL, Wynn JJ, Merion RM, Deierhoi MH, Metzger RA, Cecka JM, Harmon WE, Leichtman AB, Spital A, Blumberg E, Herzog CA, Wolfe RA, Tyan DB, Roberts J, Rohrer R, Port FK, Delmonico FL: The report of a national conference on the wait list for kidney transplantation. Am J Transplant 2003;3:775-785.
46 Joshi S, J Gaynor J, Ciancio G: Review of ethnic disparities in access to renal transplantation. Clin Transplant 2012;26:E337-E343.

47 Ayanian JZ, Cleary PD, Keogh JH, Noonan SJ, David-Kasdan JA, Epstein AM: Physicians' beliefs about racial differences in referral for renal transplantation. Am J Kidney Dis 2004; 43:350-357.

48 O'Hare AM, Johansen KL, Rodriguez RA: Dialysis and kidney transplantation among patients living in rural areas of the United States. Kidney Int 2006;69:343-349.

49 Patzer RE, Perryman JP, Pastan S, Amaral S, Gazmararian JA, Klein M, Kutner N, McClellan WM: Impact of a patient education program on disparities in kidney transplant evaluation. Clin J Am Soc Nephrol 2012;7: 648-655.
50 Sullivan C, Leon JB, Sayre SS, Marbury M, Ivers M, Pencak JA, Bodziak KA, Hricik DE, Morrison EJ, Albert JM, Navaneethan SD, Reyes CM, Sehgal AR: Impact of navigators on completion of steps in the kidney transplant process: a randomized, controlled trial. Clin J Am Soc Nephrol 2012;7:1639-1645.

51 Frankenfield DL, Krishnan SM, Ashby VB, Shearon TH, Rocco MV, Saran R: Differences in mortality among Mexican-American, Puerto Rican, and Cuban-American dialysis patients in the United States. Am J Kidney Dis 2009;53:647-657. 